\title{
COMPARISON OF CODES ASSESSING GALACTIC COSMIC RADIATION EXPOSURE OF AIRCRAFT CREW
}

\author{
J. F. Bottollier-Depois ${ }^{1, *}$, P. Beck ${ }^{2}$, B. Bennett ${ }^{3}$, L. Bennett ${ }^{3}$, R. Bütikofer ${ }^{4}$, I. Clairand ${ }^{1}$, L. Desorgher ${ }^{5}$, \\ C. Dyer ${ }^{6}$, E. Felsberger ${ }^{7}$, E. Flückiger ${ }^{4}$, A. Hands ${ }^{6}$, P. Kindl ${ }^{8}$, M. Latocha ${ }^{2}$, B. Lewis ${ }^{3}$, G. Leuthold ${ }^{9}$, \\ T. Maczka ${ }^{9}$, V. Mares ${ }^{9}$, M. J. McCall ${ }^{10}$, K. O’Brien ${ }^{11}$, S. Rollet ${ }^{2}$, W. Rühm ${ }^{9}$ and F. Wissmann ${ }^{12}$ \\ ${ }^{1}$ Institute for Radiological Protection and Nuclear Safety, F-92262 Fontenay-aux-Roses, France \\ ${ }^{2}$ Department Health and Environment, ARC, Austrian Research Centers, A-2444 Seibersdorf, Austria \\ ${ }^{3}$ Royal Military College, Kingston, ON, Canada, K7K 7B4 \\ ${ }^{4}$ University of Bern, Bern, Switzerland \\ ${ }^{5}$ SpaceIT GmbH, Bern, Switzerland \\ ${ }^{6}$ Aerospace Division, QinetiQ, Farnborough, UK \\ ${ }^{7}$ IASON GmbH, Feldkirchner Straße 4, A-8054 Graz-Seiersberg, Austria \\ ${ }^{8}$ Institute for Material Physics, Graz University of Technology, A-8010 Graz, Austria \\ ${ }^{9}$ Helmholz Zentrum München, Institute of Radiation Protection, 85758 Neuherberg, Germany \\ ${ }^{10}$ PCaire Inc., 38 Colonnade Rd, Ottawa, Canada \\ ${ }^{11}$ Department of Physics and Astronomy, Northern Arizona University, Flagstaff, AZ 86011-6010, USA \\ ${ }^{12}$ Physikalisch-Technische Bundesanstalt, Bundesallee 100, 38116 Braunschweig, Germany
}

\begin{abstract}
The assessment of the exposure to cosmic radiation onboard aircraft is one of the preoccupations of bodies responsible for radiation protection. Cosmic particle flux is significantly higher onboard aircraft than at ground level and its intensity depends on the solar activity. The dose is usually estimated using codes validated by the experimental data. In this paper, a comparison of various codes is presented, some of them are used routinely, to assess the dose received by the aircraft crew caused by the galactic cosmic radiation. Results are provided for periods close to solar maximum and minimum and for selected flights covering major commercial routes in the world. The overall agreement between the codes, particularly for those routinely used for aircraft crew dosimetry, was better than $\pm 20 \%$ from the median in all but two cases. The agreement within the codes is considered to be fully satisfactory for radiation protection purposes.
\end{abstract}

\section{INTRODUCTION}

Since 1996, aircraft crews in the European Union (EU) have been recognised as occupationally exposed workers owing to their exposure to cosmic radiation in the atmosphere. By 2006, the directive EURATOM/96/29 was implemented in all EU member states and proper measures must have been undertaken to assess the dose. Since the radiation field is very complex in terms of particle composition and particle energies, the dose assessment is a very difficult task. During the last decade, many research projects were focused on this problem. One of the main outcomes was that dose assessment can be done by using program codes that were developed during the last few years. The use of a predictive code is possible when the radiation field is rather constant and sudden changes in the local dose rates are not expected, except for the case of rarely occurring ground-level enhancements associated with solar-particle events having a high fluence rate of particles with high energy. Therefore, the time, geographical information on latitude, longitude and

*Corresponding author: jeanfrancois.bottollier@irsn.fr barometric altitude of the flown routes are the basic input parameters for any calculation.

The aim of this study is to compare the calculated dose and dose rates of those codes (see Table 1) that are mainly used in Europe and for which the providers agreed to perform the calculations. Some of the codes are routinely used for radiation protection purposes, whereas others are purely for scientific use.

For routine radiation protection purposes, i.e. dose assessment of aircraft crew, a code must be able to calculate the effective dose $E$ as the radiation protection quantity. However, the validation of codes can only be done by comparing the measured ambient dose equivalent $H^{*}(10)$ (or its rate) to the calculated value. Therefore, the ability to calculate $H^{*}(10)$ is mandatory for all codes.

The different codes used are summarised in Table 1. Some of them are based on Monte Carlo simulations of the radiation field (AVIDOS, EPCARD, QARM); one code (FREE) uses the analytical calculation of the particle transport through the atmosphere based on PLOTINUS calculations. These solutions use the evaluated particle fluxes to calculate the ambient dose equivalent and effective dose by using appropriate conversion 


\section{J. F. BOTTOLLIER-DEPOIS ET AL.}

Table 1. Computer codes for the calculation of the radiation exposure of aircraft crew due to the galactic cosmic radiation.

\begin{tabular}{|c|c|c|c|c|}
\hline Computer code & Method & $\begin{array}{l}\text { Galactic proton } \\
\text { spectra (if applied) }\end{array}$ & Cut-off rigidity & Dose conversion \\
\hline AVIDOS $1.0^{(3)}$ & $\begin{array}{l}\text { Multiparameter model } \\
\text { based on FLUKA Monte } \\
\text { Carlo calculations }\end{array}$ & $\begin{array}{l}\text { Balloon experiment } \\
\text { modified Gaisser } \\
\text { et al. }{ }^{(5)}\end{array}$ & $\begin{array}{l}\text { Vertical cut-off } \\
\text { rigidity }^{(6)}\end{array}$ & $\begin{array}{l}\text { ICRP } 60^{(1)} \text { and } \\
\text { Pelliccioni }\end{array}$ \\
\hline EPCARD.Net 5.4.0 ${ }^{(8)}$ & $\begin{array}{l}\text { Based on FLUKA } \\
\text { Monte Carlo } \\
\text { calculations }^{(4)}\end{array}$ & $\begin{array}{l}\text { Badhwar et al } \\
\text { model }^{(9)}\end{array}$ & $\begin{array}{l}\text { Vertical cut-off } \\
\text { rigidity }\end{array}$ & $\begin{array}{l}\text { ICRP } 60^{(1)} \text {, } \\
\text { Pelliccioni }{ }^{(7)} \text { and } \\
\text { Mares and } \\
\text { Leuthold }^{(11)}\end{array}$ \\
\hline $\begin{array}{l}\text { FDOScalc (F. Wissmann } \\
\text { and, M. Reginatto, in } \\
\text { preparation) }\end{array}$ & $\begin{array}{l}\text { Multiparameter fit to } \\
\text { experimental data of } \\
\text { ambient dose equivalent } \\
\text { rates }\end{array}$ & - & $\begin{array}{l}\text { Vertical cut-off } \\
\text { rigidity }^{(14)}\end{array}$ & \\
\hline FREE 1.3 .0 & $\begin{array}{l}\text { Based on analytical } \\
\text { solution to the } \\
\text { corresponding Boltzmann } \\
\text { equation }\end{array}$ & $\begin{array}{l}<10 \mathrm{GeV}^{(15)}, \\
>10 \mathrm{GeV}^{(16)}, \\
\text { normalised at } \\
10.6 \mathrm{GeV}^{(17)}\end{array}$ & $\begin{array}{l}\text { Vertical cut-off } \\
\text { rigidity }{ }^{(18)} \text { and } \\
\text { non-vertical cut- } \\
\text { off rigidities }^{(19)}\end{array}$ & $\begin{array}{l}\text { ICRP } 60^{(1)} \text { and } \\
\text { Pelliccioni et al. }\end{array}$ \\
\hline PCAIRE & $\begin{array}{l}\text { Semi-empirical: } \\
\text { measurement-based with } \\
\text { modeled } E / H^{*}(10) \\
\text { conversion } 20-23)\end{array}$ & - & $\begin{array}{l}\text { Vertical cut-off } \\
\text { rigidity }^{(21)}\end{array}$ & $\operatorname{ICRP} 60^{(1)}$ \\
\hline $\begin{array}{l}\text { PLANETOCOSMICS } \\
2.0^{(14)}\end{array}$ & $\begin{array}{l}\text { GEANT4 based Monte } \\
\text { Carlo simulation of the } \\
\text { nucleonic-electromagnetic } \\
\text { cascade }\end{array}$ & $\begin{array}{l}\text { Gleeson and } \\
\text { Axford }^{(24)} \text {, Garcia- } \\
\text { Munoz et al. }\end{array}$ & $\begin{array}{l}\text { Vertical cut-off } \\
\text { rigidity }^{(10)}\end{array}$ & $\begin{array}{l}\text { ICRP } 60^{(1)} \text { and } \\
\text { Pelliccioni }\end{array}$ \\
\hline QARM $1.0^{(25-27)}$ & $\begin{array}{l}\text { Based on MCNPX } \\
\text { Monte Carlo transport } \\
\text { calculation }^{(28)}\end{array}$ & $\begin{array}{l}\text { Badwar et al. } \\
\text { model }^{(9)}\end{array}$ & $\begin{array}{l}\text { Vertical cut-off } \\
\text { rigidity }(29)\end{array}$ & $\begin{array}{l}\text { ICRP } 74^{(30)} \text { and } \\
\text { Pelliccioni }^{(7)}\end{array}$ \\
\hline SIEVERT $1.0^{(31)}$ & $\begin{array}{l}\text { Operational code using } \\
\text { EPCARD } 3.34 \text { to create } \\
\text { the input dose rate } \\
\text { maps }^{(32)}\end{array}$ & - & - & - \\
\hline
\end{tabular}

coefficients as recommended by ICRP Publication $103^{(1)}$. Other codes are based on measurements only (FDOScalc, PCAIRE) and partly use the $E / H^{*}(10)$ conversion as calculated by the Monte Carlo based codes. The codes EPCARD 3.34 ${ }^{(2)}$, FREE 1.3.0 and PCAIRE are approved by the civil aviation authority in Germany. For this comparison, the new version EPCARD.Net 5.4.0, which is not yet approved in Germany, and the scientific version of PCAIRE, also not approved in Germany, were used. In Austria, ARCS is accredited for computational aircrew dosimetry with the code AVIDOS 1.0 and IASON with the code FREE 1.3.0. Both qualifications are valid in whole Europe according to European regulations of accreditation. The code SIEVERT 1.0, which uses a worldwide grid of dose rates calculated with EPCARD 3.34, was initiated by the French aviation authority to provide a common tool for airlines. The early version of EPCARD 3.0 was partly supported by the European Commission and used as the physical basis for the most modern version EPCARD.Net developed by Helmholtz Zentrum München.

\section{MATERIALS AND METHODS}

The comparison was organised in such a way that routes flown by typical passenger aircraft were obtained from different airlines. The input format uses the coordinates of the departure and arrival airport. Several way points in-between were defined where the altitudes and/or course have changed. The code providers were asked to calculate the total route dose as well as the local dose rates at the given way points in terms of $H^{*}(10)$ and, if possible, in $E$. Results should be given both for a period close to solar maximum (07/2000) and minimum (09/2007). The selected 23 flights cover all major routes of passenger flights in the world (see Figure 1) as well as a wide range of latitudes (from North to South) and also a wide range of vertical cut-off rigidities (from 0 to $18 \mathrm{GV})$. They also included seven Ultra Long Range flights with flight durations of more than $13 \mathrm{~h}$.

Additionally, one specific flight (Singapore to Newark, No. 23 in Figure 2) was selected, and the codes were used to calculate dose rates $\left(\mathrm{d} H^{*}(10) / \mathrm{d} t\right.$ and $\mathrm{d} E / \mathrm{d} t$ ) for the way points along the flight route. 
This flight was chosen because it covers a wide range of vertical cut-off rigidities from almost 0 to about 17 GV. All results were collected by one single partner so that the participants were not aware of the other results until all were presented during a common meeting where all authors were invited.

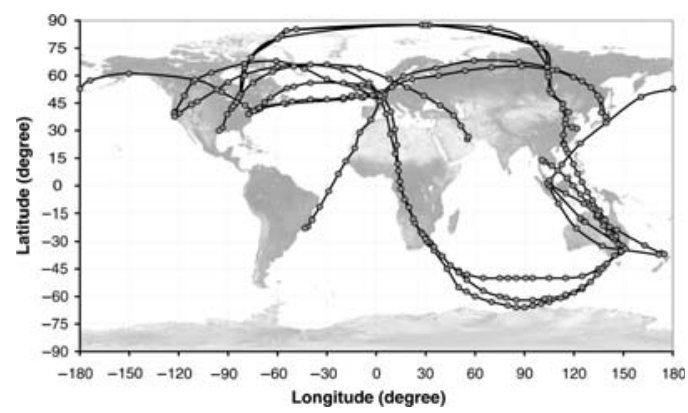

Figure 1. The selected flight routes of the 23 investigated flights cover a wide latitude range from the northern to the southern hemisphere. Grey dots denote way points with latitude, longitude, altitude and time of flight.
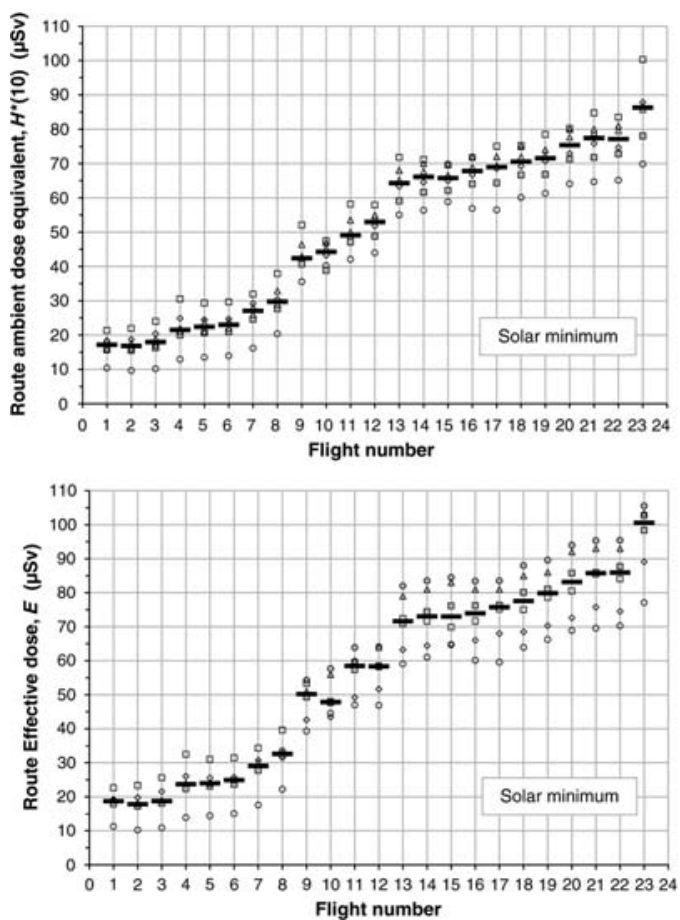

\section{DOSE COMPARISONS}

Anonymous dose comparisons of the calculated data for 23 investigated flights were done in terms of effective dose $E$ and ambient dose equivalent $H^{*}(10)$ for seven computer codes. PLANETOCOSMICS is not part of any further comparisons.

Figure 2 shows anonymous comparisons of the total ambient dose equivalent $H^{*}(10)$ (two diagrams on top) and effective dose $E$ (two diagrams on bottom) at different mid- and long-haul flights due to the galactic cosmic radiation, during solar minimum (left diagrams) and solar maximum (right diagrams) conditions. The results are calculated by the codes AVIDOS 1.0, EPCARD.Net 5.4.0, FDOScalc, FREE 1.3.0, PCAIRE, QARM 1.0 and SIEVERT 1.0. The 23 investigated flights are sorted according their route doses.

Some of the computer codes seem not to agree with the majority; therefore, the median of the data was investigated in more detail. All medians of the data are marked as black bars. Not all codes are investigated in all four diagrams of Figure 2. To quantify the deviation of the median, a comparison of the deviation of the $H^{*}(10)$ (two diagrams on
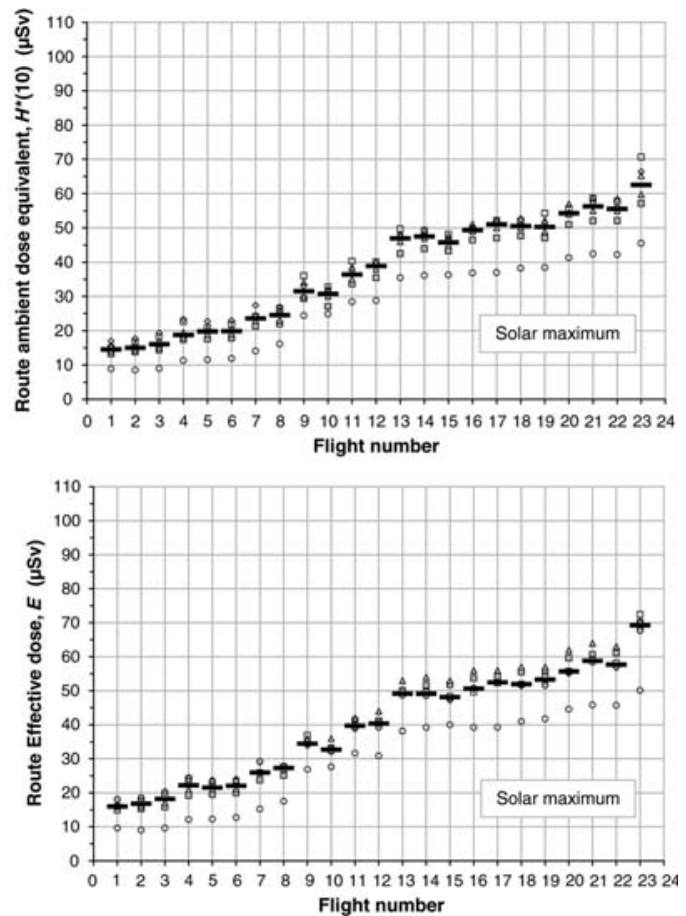

Figure 2. Anonymous comparison of the total ambient dose equivalent $H^{*}(10)$ (two figures on top) and effective dose $E$ (two figures on bottom) at different mid- and long-haul flights due to the galactic cosmic radiation, during solar minimum (left figures) and solar maximum (right figures) conditions. The results are calculated by the computer codes AVIDOS 1.0, EPCARD.Net 5.4.0, FDOScalc, FREE 1.3.0, PCAIRE, QARM 1.0 and SIEVERT 1.0. Median is marked as black bar. Not all codes provide both quantity $H^{*}(10)$ and effective dose $E$ and are therefore not shown in all four figures. 


\section{J. F. BOTTOLLIER-DEPOIS ET AL.}
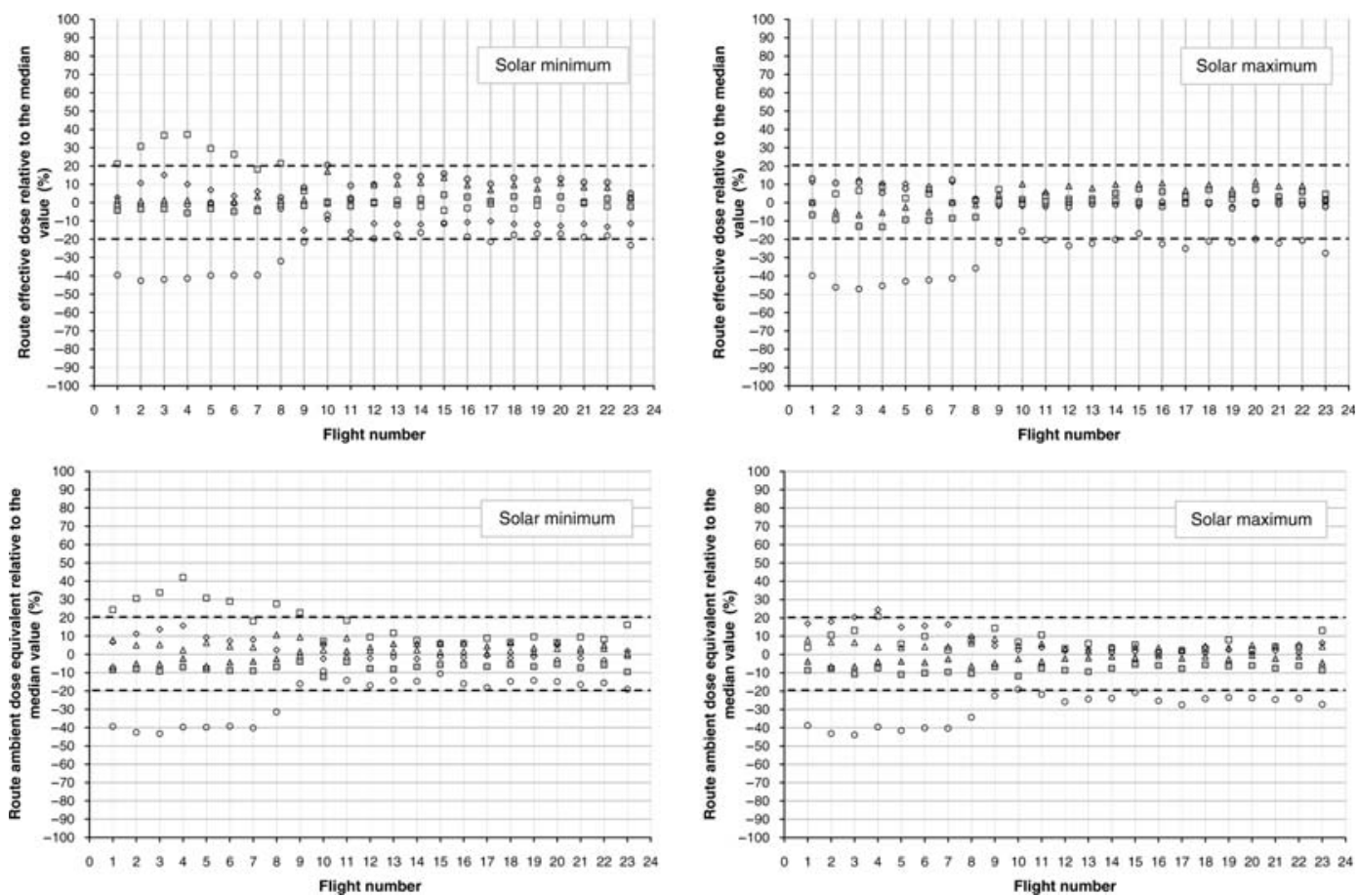

Figure 3. Anonymous comparison of the relative to the median deviation of the $H^{*}(10)$ (two figures on top) and the effective dose $E$ (two figures on bottom) at different mid- and long-haul flights due to the galactic cosmic radiation, at solar minimum (left figures) and solar maximum (right figures). The results are calculated by the computer codes AVIDOS 1.0, EPCARD.Net 5.4.0, FDOScalc, FREE 1.3.0, PCAIRE, QARM 1.0 and SIEVERT 1.0. Not all codes provide both quantity $H^{*}(10)$ and effective dose $E$ and are therefore not shown in all four figures.

top) and the effective dose $E$ (two diagrams on bottom), relative to the median, at solar minimum (left diagrams) and solar maximum (right diagrams) was made in Figure 3. Note again that not all codes are investigated in all four diagrams. Since the 23 investigated flights are sorted according to their route doses, the increasing deviation to the median is obviously present for lower route doses, but not for the larger ones. Furthermore, dose rate data were investigated along a specific long-haul flight route. Figure 4 shows the comparison of the radiation exposure profile of a flight route from Singapore to Newark in terms of ambient dose equivalent rate $\mathrm{d} H^{*}(10) / \mathrm{d} t$ (two diagrams on top) and the effective dose rate $\mathrm{d} E / \mathrm{d} t$ (two diagrams on bottom) due to the galactic cosmic radiation, at solar minimum (left diagrams) and solar maximum (right diagrams).

The results are calculated by the seven computer codes AVIDOS 1.0, EPCARD.Net 5.4.0, FDOScalc, FREE 1.3.0, PCAIRE, QARM 1.0 and SIEVERT 1.0. The medians are marked as black bars for each individual dose rate at each position.

\section{DISCUSSION ON RESULTS}

In Figure 2, the results obtained by the different codes for the selected flights are summarised, both in terms of $H^{*}(10)$ and, if given by the code, the effective dose $E$. Clearly, the rough trend of increasing doses for flights 1-23 was reproduced by all codes. As expected, doses for a certain flight calculated at solar minimum are higher than those calculated at solar maximum, due to the lower shielding effect of the solar (interplanetary) magnetic field against the galactic component of cosmic radiation during the solar minimum. Similarly, the calculated results for shorter flights at lower latitudes result in lower doses $\left(H^{*}(10)\right.$ or $\left.E\right)$ than those for longer flights at higher latitudes, reflecting the flight time and the shielding effect of the geomagnetic field to be important parameters for the dose from cosmic radiation.

In order to compare the results in more detail, Figure 3 shows the same data, but normalised to the median of the doses obtained by the various codes for a certain flight. There is only one code that produces 

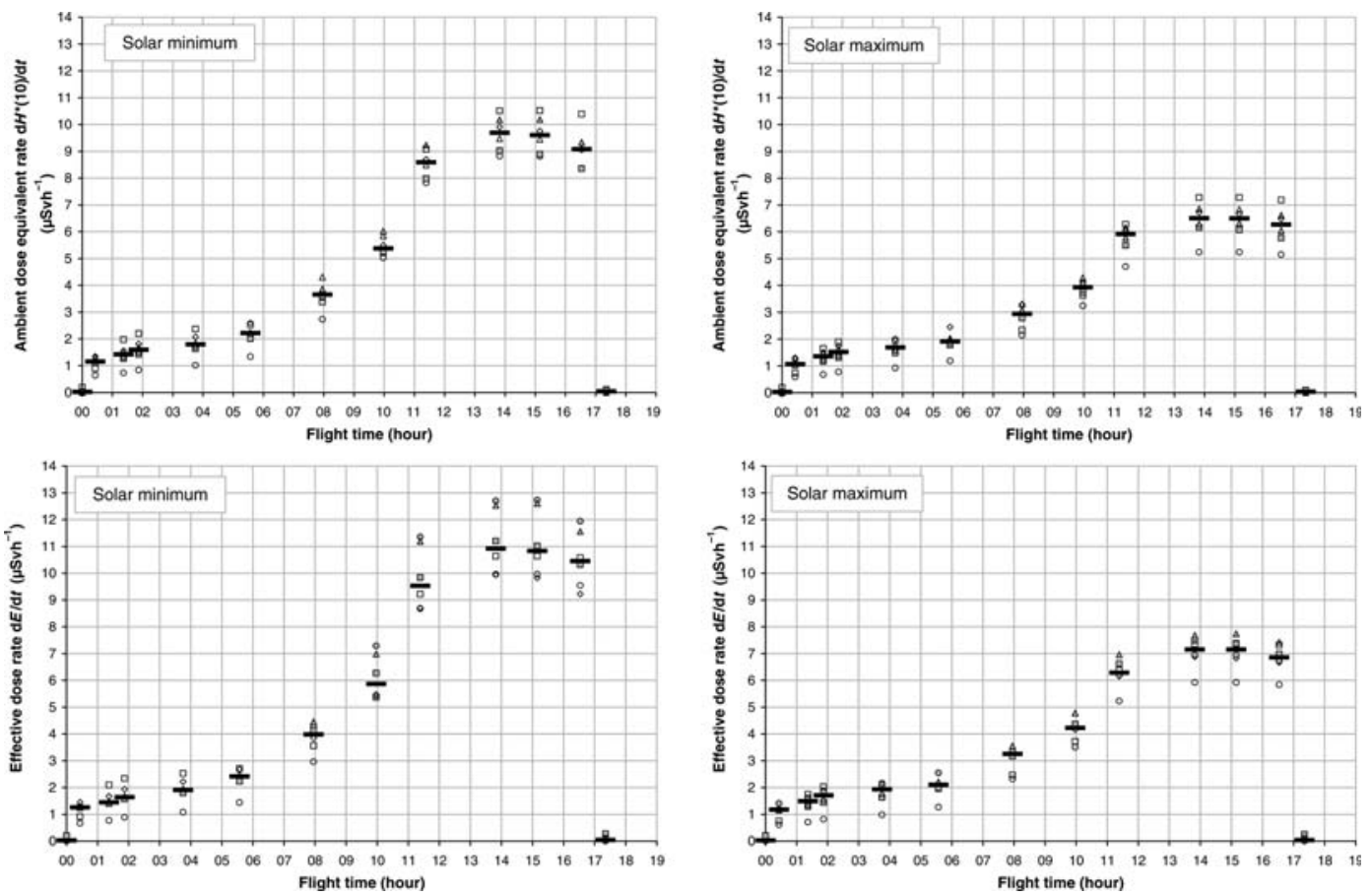

Figure 4. Anonymous comparison of the radiation exposure profile of a flight route form Singapore to Newark in terms of ambient dose equivalent rate $\mathrm{d} H^{*}(10) / \mathrm{dt}$ (two figures on top) and the effective dose rate $\mathrm{d} E / \mathrm{dt}$ (two figures on bottom) due to galactic cosmic radiation, at solar minimum (left figures) and solar maximum (right figures). The results are calculated by the computer codes AVIDOS 1.0, EPCARD.Net 5.4.0, FDOScalc, FREE 1.3.0, PCAIRE, QARM 1.0 and

SIEVERT 1.0. Median is marked as black bar. Not all codes are investigated in all four figures.

significantly lower doses than all the other codes for all flights (open circles in Figure 2). For short flights at low latitudes, doses from this code are as much as about $40 \%$ lower than the median (open circles in Figure 3). Another code reports slightly higher values for some lower dose flights, for solar minimum (open squares in Figures 1 and 2). In general, however, Figure 3 demonstrates that for most flights and codes, the calculated doses $\left(H^{*}(10)\right.$ or $\left.E\right)$ differ less than about $\pm 20 \%$ from their median.

Results obtained for the selected flight from Singapore to Newark are given in Figure 4. Again the dose rate pattern as obtained from the participating codes as a function of flight time (i.e. at the different way points) is very similar. The pattern reflects the flight profile that was at flight level 300 after the start (corresponding to an altitude of $9.1 \mathrm{~km}$ ), and increased up to flight level 410 (corresponding to an altitude of $12.5 \mathrm{~km}$ ) before the descent was initiated. It also reflects the change in geomagnetic cut-off rigidity, representing the ability for a charge particle to penetrate the geomagnetic field, which was high in Singapore (about $17 \mathrm{GV}$ ), and decreased to a minimum of almost $0 \mathrm{GV}$ about $4 \mathrm{~h}$ before Newark was reached (at about $2 \mathrm{GV}$ ).
Again, one code provided systematically lower dose values than the other codes (open circle in Figure 4). The results given by the other participating codes differ less than about $\pm 20 \%$ from their median, in terms of the dose rates calculated for each of the given way points. It should be noted that the median does not necessarily represent the most correct value of the doses calculated.

From an overview of the results, it was noted that (data not shown) the dose and dose rate values as given by the participating codes also reflect the dependence of dose on altitude and vertical cut-off rigidity in a very similar way.

\section{CONCLUSIONS}

Eight codes used for calculating doses to pilots and cabin crew members have participated in a comparison exercise organised by the EURADOS Working Group 5 on Air Crew Dosimetry, in an effort to provide advice for harmonisation of aircrew dosimetry practices in European countries. Some of these codes are based on the simulation of the secondary field of cosmic radiation by means of Monte Carlo techniques; others use analytical solutions of the 


\section{J. F. BOTTOLLIER-DEPOIS ET AL.}

problem, while still others are mainly based on an adaptation to the experimental data. There was one code that provided systematically lower dose and dose rate values (up to $-40 \%$ at low latitudes compared with the median) than all the other participating codes, while another code showed a few dose and dose rate values that were higher by some $+30 \%$ (also at low latitude). The overall agreement between the codes, however, was better than $\pm 20 \%$ from the median. This agreement is particularly true for those codes that are routinely used for aircraft crew dosimetry.

The agreement between the codes, which are mostly theoretically based, while a few are experimentally based, is considered to be fully satisfactory. Actually, in radiation protection, dose estimates generally include uncertainties no better than \pm 20 $30 \%$. This conclusion is further substantiated by the fact that most of these codes have also been validated by measurements ${ }^{(33)}$ in the past, in which an agreement between measured and calculated doses better than $\pm 20 \%$ was achieved.

\section{REFERENCES}

1. ICRP. The 2007 Recommendations of the International Commission on Radiological Protection. ICRP Publication 103. Ann. ICRP 37(2-4) (2007).

2. Schraube, H., Leuthold, G., Heinrich, W., Roesler, S., Mares, V. and Schraube, G. EPCARD-European Program Package for the Calculation of Aviation Route Doses, User's Manual. ISSN 0721-1694. GSF-Report 08/02 (2002).

3. Beck, P., Latocha, M., Rollet, S., Dormann, L. and Pelliccioni, M. Measurements and simulation of the radiation exposure to aircraft crew workplaces due to cosmic radiation in the atmosphere. Radiat. Prot. Dosimetry 126(1-4), 564-567 (2007).

4. Roesler, S., Heinrich, W. and Schraube, H. Monte Carlo calculation of the radiation field at aircraft altitudes. Radiat. Prot. Dosimetry 98(4), 367-388 (2002).

5. Gaisser, T. K., Honda, M., Lipari, P. and Stanev, T. Primary spectrum to $1 \mathrm{TeV}$ and beyond. Proceedings of the 27th International Cosmic Ray Conference (ICRC 2001), Hamburg, Germany, 643-646, 7-15 August 2001.

6. Smart, D. F. and Shea, M. A. World grid of cosmic ray vertical cut-off rigidities for Epoch 1990. Proceedings of 25th International Cosmic Ray Conference, Durban, South Africa, 401-404 (1997).

7. Pelliccioni, M. Overview of fluence-to-effective dose and fluence-to-ambient dose equivalent conversion coefficients for high energy radiation calculated using FLUKA code. Radiat. Prot. Dosimetry 88(4), 279-297 (2000).

8. Mares, V., Maczka, T., Leuthold, G. and Rühm, W. Air crew dosimetry with the new EPCARD. Net code. Radiat. Prot. Dosimetry, this issue.

9. Badhwar, G. D., O’Neill, P. M. and Troung, A. G. Galactic cosmic radiation environmental model. Private communication (2000).

10. Bütikofer, R., Flückiger, E. O. and Desorgher, L. Characteristics of near real-time cutoff calculations on a local and global scale. 30th International Cosmic Ray Conference, Mérida, México (2007).

11. Mares, V. and Leuthold, G. Altitude-dependent dose conversion coefficients in EPCARD. Radiat. Prot. Dosimetry 126(1-4), 581-584 (2007).

12. Schrewe, U. J. Global measurements of the radiation exposure of civil air crew from 1997 to 1999. Radiat. Prot. Dosimetry 91(4), 347-364 (2000).

13. Wissmann, F. Long-term measurements of $H^{*}(10)$ at aviation altitudes in the northern hemisphere. Radiat. Prot. Dosimetry 121(4), 347-357 (2006).

14. http://cosray.unibe.ch/ laurent/planetocosmics/.

15. Garcia-Munoz, M., Mason, G. M. and Simpson, J. A. The Annomalous ${ }^{4} \mathrm{He}$ component in the cosmic ray spectra of $\leq 50 \mathrm{MeV}$ per $Z$ nucleon during 1972-1974. Astrophys. J. 202, 265 (1975).

16. Peters, B. In: Handbook of Physics. Condon, E. U. and Odishaw, H. Eds. (New York, McGraw-Hill Co), 9/ 207-45 (1958).

17. Gaisser, T. K. and Stanev, T. Cosmic rays. European Phys. J. C 3, 132-137 (1998).

18. Shea, M. A. and Smart, D. F. Cosmic ray implications for human health. Space Sci. Rev. 93, 187-205 (2000).

19. Heinrich, W. and Spill, A. Geomagnetic shielding of cosmic rays for different satellite orbits. J. Geophys. Res. 84(A8), 4401-4004 (1979).

20. Lewis, B. J., McCall, M. J., Green, A. R., Bennett, L. G. I., Pierre, M., Schrewe, U. J., O'Brien, K. and Felsberger, E. Aircrew exposure from cosmic radiation on commercial airline routes. Radiat. Prot. Dosimetry 93(4), 293-314 (2001).

21. Lewis, B. J., Bennett, L. G. I., Green, A. R., McCall, M. J., Ellaschuk, B., Butler, A. and Pierre, M. Galactic and solar radiation exposure to aircrew during a solar cycle. Radiat. Prot. Dosimetry 102(3), 207-227 (2002).

22. Lewis, B. J., Desormeaux, M., Green, A. R., Bennett, L. G. I., Butler, A., McCall, M. and Saez Vergara, J. C. Assessment of aircrew radiation exposure by further measurements and model development. Radiat. Prot. Dosimetry 111(2), 151-171 (2004).

23. Takada, M., Lewis, B. J., Boudreau, M., Al Anid, H. and Bennett, L. G. I. Modelling of aircrew radiation exposure from galactic cosmic rays and solar particle events. Radiat. Prot. Dosimetry 124(4), 289-318 (2007).

24. Gleeson, L. J. and Axford, W. I. Solar modulation of galactic cosmic rays. Astrophys. J. 154, 1011 (1968).

25. Lei, F., Clucas, S., Dyer, C. and Truscott, P. An atmospheric radiation model based on response matrices generated by detailed Monte Carlo simulations of cosmic ray interactions. IEEE Trans. Nucl. Sci. 51(6), 3442-3451 (2004).

26. Lei, F., Hands, A., Dyer, C. and Truscott, P. Improvements to and validations of the QinetiQ Atmospheric Radiation Model (QARM). IEEE Trans. Nucl. Sci. 53(4), 1851-1858 (2006).

27. Dyer, C., Lei, F., Hands, A. and Truscott, P. Solar particle events in the QinetiQ Atmospheric Radiation Model. IEEE Trans. Nucl. Sci. 54(4), 1071-1075 (2007).

28. MCNPX home page: http://monpx.lanl.gov.

29. Desorgher, L. MAGNETOSCOSMICS Users' Manual, 2003. http://reat.space.qinetiq.com/septimess/magcos.

30. ICRP. Conversion coefficients for use in radiological protection against external radiation. ICRP Publication 74. Ann. ICRP 26(3-4) (1996). 
31. SIEVERT home page: http://www.sievert-system.org.

32. Bottollier-Depois, J. F., Blanchard, P., Clairand, I., Dessarps, P., Fuller, N., Lantos, P., Saint-Lô, D. and Trompier, F. An operational approach for aircraft crew dosimetry: the SIEVERT system. Radiat. Prot. Dosimetry 125(1-4), 421-424 (2007).
33. Lindborg, L., Bartlett, D., Beck, P., McAulay, I., Schnuer, K., Schraube, G. and Spurny, F. EURADOS. Cosmic radiation exposure of aircraft crew: compilation of measured and calculated data. Luxembourg, Belgium, European Commission, Office for Official Publication of the European Communities, 1-271 (2004). 